\title{
A CONSTRUÇÃO DE UM CURRÍCULO MÉDICO BASEADO NA PERSPECTIVA DA ANDRAGOGIA: ESTAMOS NO CAMINHO CORRETO?
}

\author{
PEDRO FONSECA DE VASCONCELOS ${ }^{1}$, RITA DE CÁSSIA SILVA \\ TAGLIAFERRE ${ }^{2}$, MAURO FERNANDES TELES ${ }^{3}$.
}

\begin{abstract}
${ }^{1}$ Mestre em Ciências Biológicas. Doutorando na Universidade Estadual do Sudoeste da Bahia, campus Jequié. Docente nas Faculdades Santo Agostinho, Vitória da Conquista/Bahia.

${ }^{2}$ Doutora em Ciências da Linguagem/ Linguística (UTAD/UNICAMP). Docente nas Faculdades Santo Agostinho, Vitória da Conquista/Bahia

${ }^{3}$ Mestre em Saúde Pública. Doutorando na Universidade Estadual do Sudoeste da Bahia, campus Jequié. Docente nas Faculdades Santo Agostinho, Vitória da Conquista/Bahia, e Faculdade Independente do Nordeste.
\end{abstract}

\section{RESUMO}

Nos últimos anos, com o avanço das tecnologias, tornou-se necessário trabalhar com novas metodologias em sala de aula. No curso de medicina, os alunos assumem o compromisso de participar ativamente do processo de aprendizagem, sendo essa uma condição para aprendizagem pautada nos princípios da Andragogia. O objetivo deste trabalho foi analisar se as Diretrizes Curriculares Nacionais norteiam a construção de um curso médico que se adeque à condição do indivíduo adulto e suas formas de aprender. Os resultados apontaram que a construção de cursos de Medicina pautados em uma perspectiva andragógica devem englobar desde uma estrutura física adequada até um modo de avaliar qualitativo e condizente com a forma de aprender do adulto. Ainda há o que evoluir na elaboração de uma DCN's que contemple todos os requisitos do modelo andragógico. Portanto, pode-se dizer que a Andragogia está evoluindo e se tornando uma abordagem importante no aprendizado das Ciências Médicas, salutar na condução do adulto-aprendiz.

Palavras-chave: Educação; Adulto; Medicina.

\section{THE CONSTRUCTION OF A MEDICAL CURRICULUM BASED ON THE PERSPECTIVE OF ANDRAGOGY: ARE WE ON THE RIGHT PATH?}

\begin{abstract}
In recent years, with the advancement of technologies, it has become necessary to work with new methodologies in the classroom. In the medical course, students are committed to actively participate in the learning process, which is a condition for
\end{abstract}


learning based on the principles of Andragogy. The objective of this work was to analyze whether the National Curriculum Guidelines guide the construction of a medical course that suits the condition of the adult individual and their ways of learning. The results pointed out that the construction of medical courses based on an andragogical perspective must encompass from an adequate physical structure to a way of evaluating qualitative and consistent with the adult's way of learning. There is still room for improvement in the development of a DCN's that addresses all the requirements of the andragogical model. Therefore, it can be said that Andragogy is evolving and becoming an important approach to learning in Medical Sciences, healthy in the conduct of adult-learners.

Keywords: Education; Adult; Medicine.

\section{INTRODUÇÃO}

A presente pesquisa surge da seguinte pergunta: "Os cursos médicos preconizam uma aprendizagem pautada no modelo andragógico?”. Sendo assim, para responder tal questionamento, o objetivo do artigo foi analisar se as Diretrizes Curriculares Nacionais (DCN's) norteiam a construção de um curso médico que se adeque à condição do adulto-aprendiz.

$\mathrm{O}$ interesse em mensurar as atividades utilizadas pelos professores que utilizam a Andragogia como um suporte em suas aulas se justifica, pois o curso de Medicina pauta-se em metodologias ativas de aprendizagem, segundo recomendação das DCN's (BRASIL, 2014).

O presente trabalho trata-se de uma pesquisa documental, de caráter qualitativo, lançando mão da análise da Resolução $n^{\circ} 3$, de 20 de junho de 2014, que institui as Diretrizes Curriculares Nacionais para os cursos de graduação em Medicina.

A análise de tal documento foi realizada com vistas a responder a questão norteadora deste estudo e os critérios avaliados foram selecionados com base nos requisitos andragógicos para efetivação de uma metodologia de ensino adequada à condição adulta, propostos por Knowles (1980). Os requisitos avaliados nas DCN's foram: a) o clima da aprendizagem; b) o diagnóstico de necessidades; c) a formulação de programas objetivos; d) envolvimento dos estudantes no processo de planejamento do aprender e professores como guia; e) a condução da experiência do ensinoaprendizagem como um processo de mútua responsabilidade entre alunos e professores; f) a avaliação da aprendizagem. 
Os dados foram analisados com base na Técnica de Análise do Conteúdo de Bardin (2011). Essa técnica possui a finalidade de "obter, por meio de procedimentos sistemáticos e objetivos de descrição de conteúdo das mensagens, indicadores (quantitativos ou não) que permitam a inferência de conhecimentos relativos às condições de produção/recepção (variáveis inferidas) destas mensagens" (BARDIN, 2011, p.47).

O plano de análise procedeu pela constituição do corpus, leitura flutuante, recorte em unidades de sentido, construção do inventário e campo semântico, codificação e categorização e interpretação dos resultados. Assim, emergiram as seguintes categorias de análise: a construção de um ambiente propício para aprendizagem; protagonismo do estudante e professor facilitador; a organização do currículo na perspectiva andragógica e; a avaliação para o progresso.

Neste sentido, inicia-se a discussão com uma reflexão acerca da prática andragógica e suas bases aplicadas à Educação Médica na contemporaneidade. E, posteriormente, empreendemos a análise das DCN's à luz dos princípios que regem a Andragogia, buscando a compreensão da regulamentação de cursos médicos pautados em um modelo que valorize o modo de aprender dos jovens e adultos.

\section{A PRÁTICA ANDRAGÓGICA NA EDUCAÇÃO MÉDICA}

O termo Andragogia surgiu, no final do século XIX, mas passou a ganhar adeptos na segunda metade do século XX, atingindo interessados das mais diversas áreas, como as das ciências da saúde. Andragogia deriva das palavras gregas andrós, que significa homem, e gogia que quer dizer comandar, conduzir, guiar.

A Andragogia, em sentido lato, pode ser definida como o guia ou a condução de pessoas adultas (DARBYSHIRE, 1993). O conceito de adulto pode ser defendido como um indivíduo maduro o suficiente para assumir as responsabilidades por seus atos diante da sociedade (OLIVEIRA, 2011; BELLAN, 2005).

A ideia de que a aprendizagem da criança seja diferente do adulto não é moderna. De acordo com Ho. E (1991), alguns trabalhos de pedagogos humanistas como Carl Rogers e Paulo Freire, bem como os de filósofos existencialistas como Sartre e pensadores como Rousseau apontam essas diferenças. Como o desenvolvimento de 
várias pesquisas, a partir dos anos 1970, nos Estados Unidos, diversos estudos foram publicados sobre o tema Andragogia, mas só a partir dos anos 1980 que ela passou a ser utilizada em outros países.

Segundo Knowles, Swanson e Holto (2009), a andragogia está estruturada em seis pilares que apontam as diferenças entre a criança e o adulto na categoria de aprendizes. O amadurecimento torna as pessoas independentes e responsáveis pelos seus atos; direcionam seus interesses; acumulam experiências fundamentando sua aprendizagem; direcionam o desenvolvimento das habilidades que aplicam para o desempenho social e em sua profissão; tem como princípio a aplicação prática do que aprendem, reduzindo o interesse por conhecimentos que tenham o futuro distante, sendo impulsionados pelas motivações internas.

No que tange a Educação Médica, observa-se, por seus postulados de autoaprendizagem direcionada, que existem teorias específicas sobre seus modelos. $\mathrm{Na}$ legislação do Sistema Único de Saúde, encontra-se uma preocupação com a formação dos profissionais da saúde no sentido de que sejam preparados para novas práticas. Essas devem estar alinhadas aos métodos de ensino que contemplem questões como educação em saúde, produção de conhecimento, educação permanente, dentre outros (XAVIER; KOIFMAN, 2011).

Pesquisas apontam que o sucesso da aprendizagem nas Ciências da Saúde está relacionado às estratégias adequadas para favorecer a assimilação do conhecimento, desenvolvimento de habilidades e incorporação de valores, favorecendo, assim, a mudança de hábitos do profissional de saúde, o que favorece para a sua formação profissional (BRASIL, 2009).

Uma das vantagens do modelo andragógico é estimular o profissional a mudar sua atitude na relação de ensino, invertendo o comando da situação, que passa para o aprendiz, que menciona o que quer e deseja aprender. Outra vantagem expressiva está no fato de a educação ocorrer a todo o momento e em todos os lugares. Assim, o conhecimento dos princípios da andragogia pelos responsáveis pelo ensino na educação de pacientes, formação profissional e educação permanente, parece ser uma ferramenta bastante útil para aquisição de melhores resultados na aprendizagem (DRAGANOV; FRIEDLÄNDER; SANNA, 2011). 
Nesse panorama, que se refere às Ciências da Saúde, a Andragogia se torna a arte e a ciência de conduzir adultos ao aprendizado, é um meio para o embasamento de estratégias que contribuam para efetivar o processo de ensino-aprendizagem. Seus princípios devem ser levados em consideração desde a concepção de um curso, materializados nas diretrizes que o regem.

\section{A CONSTRUÇÃO DE UM AMBIENTE PROPÍCIO PARA APRENDIZAGEM}

Knowles (1980) acredita que, para efetivar uma educação pautada no modelo andragógico, todas as dimensões do indivíduo envolvido no processo ensinoaprendizagem e seu contexto de vida devem ser analisadas. $\mathrm{O}$ ambiente físico em que se aprende deve ser apropriado, desde uma iluminação adequada até a decoração do espaço.

As DCN's para o curso médico não explicitam a necessidade da construção desses espaços, deixando de salientar a relevância de se construir ambientes propícios para aprendizagem. A resolução apenas indica, em seu parágrafo IV, no artigo $7^{\circ}$, que o graduando em Medicina deve “aprender em situações e ambientes protegidos e controlados, ou em simulações da realidade, identificando e avaliando o erro, como insumo da aprendizagem profissional e organizacional e como suporte pedagógico" (BRASIL, 2014, p. 3).

Tal fato, leva-nos a refletir sobre a inserção do acadêmico nesses ambientes reais como forma de desenvolver habilidades práticas no uso de sua profissão. Entende-se que o adulto, quando na qualidade de aprendiz, direciona sua intencionalidade de aprender para aquilo que lhes é útil, no âmbito profissional e social, sentindo-se motivado a tal em espaços que simulem a realidade (KNOWLES, HOLTON, SWASON, 2009). Contudo, nada é dito no que tange ao ambiente educativo informal, confortável, seguro, respeitoso e confiante para propiciar o sucesso de aprendizagem (NOGUEIRA, 2004).

Desse modo, para a interpretação desse requisito andragógico, o clima de aprendizagem fica a cargo do leitor que precisa identificar o dito no não dito. Portanto, vale-se da compreensão de que, para construir um curso, lançando mão de metodologias ativas de aprendizagem, faz-se necessário a construção de um ambiente em que estimule 
a criatividade, o senso crítico, a inovação e o protagonismo do estudante. Segundo Fujita et al. (2016), esses são pilares de uma metodologia ativa e, pensando que essas metodologias, por suas características, vão de encontro ao pensamento andragógico.

Entretanto, vale ressaltar que é preciso indicar, nas DCN's, que esse ambiente seja favorável à consolidação de um pensamento positivo e proativo, funcionando como facilitador do processo de ensino-aprendizagem aos adultos.

\section{PROTAGONISMO DO ESTUDANTE E PROFESSOR FACILITADOR}

Compreender que o aprendiz é "dono" e centro no seu processo de aprendizagem é uma premissa básica na Andragogia. Knowles, Holton e Swason (2006; 2009) acreditam que, para superar os limites da Pedagogia, a Andragogia utiliza de alguns princípios, dentre eles o de que o adulto supre sua necessidade de aprender de forma independente, sendo capaz de se autodesenvolver. As DCN's reafirmam no artigo $7^{\circ}$ que diz

Art. $7^{\circ} \mathrm{Na}$ Educação em Saúde, o graduando deverá corresponsabilizar-se pela própria formação inicial, continuada e em serviço, autonomia intelectual, responsabilidade social, ao tempo em que se compromete com a formação das futuras gerações de profissionais de saúde, e o estímulo à mobilidade acadêmica e profissional, objetivando:

I - aprender a aprender, como parte do processo de ensino-aprendizagem, identificando conhecimentos prévios, desenvolvendo a curiosidade e formulando questões para a busca de respostas cientificamente consolidadas, construindo sentidos para a identidade profissional e avaliando, criticamente, as informações obtidas, preservando a privacidade das fontes;

II - aprender com autonomia e com a percepção da necessidade da educação continuada, a partir da mediação dos professores e profissionais do Sistema Único de Saúde, desde o primeiro ano do curso;

III - aprender interprofissionalmente, com base na reflexão sobre a própria prática e pela troca de saberes com profissionais da área da saúde e outras áreas do conhecimento, para a orientação da identificação e discussão dos problemas, estimulando o aprimoramento da colaboração e da qualidade da atenção à saúde;

IV - aprender em situações e ambientes protegidos e controlados, ou em simulações da realidade, identificando e avaliando o erro, como insumo da aprendizagem profissional e organizacional e como suporte pedagógico (BRASIL, 2014, p.3).

Uma aprendizagem só é significativa se o estudante é ativo e participa do processo ensino-aprendizagem, levando em conta conhecimento prévio desse aprendiz e possibilitando a construção de novos conceitos (subsunçores) (AUSUBEL, 2003). Esse aprendizado é baseado na intencionalidade e no material significativo que é apresentado 
ao aprendiz. O trecho acima explicita isso ao trazer a relevância da autonomia do graduando de Medicina, responsabilização mútua por seu modo de aprender e a inserção na prática para buscar um conhecimento intencional. E mostra que o aprender pode acontecer em diferentes espaços, gerando a motivação, princípio básico da Andragogia, proposto por Knowles (2006).

Para isso, é necessário assumir uma postura que permita a transformação da própria prática, facilitada pelo fato do curso médico ter que "utilizar metodologias que privilegiem a participação ativa do aluno na construção do conhecimento e na integração entre os conteúdos" (BRASIL, 2014, p.12). Diversos autores coadunam em dizer que o uso de metodologias ativas promove um pensamento reflexivo, crítico e imbricado com a realidade vivida pelo estudante-adulto (CEZAR et al. 2010; ARAGÃO, SOARES, 2014; FORTE et al. 2015).

Nessa perspectiva, o professor precisa mudar de postura, pois não cabe mais um docente que se dedica a colocar o estudante em um plano de dependência (OLIVEIRA, 1999). O professor precisa assumir um papel de facilitador/catalisador do conhecimento para garantir uma educação para adultos no modelo andragógico (KNOWLES, 1980). Assim é preconizado que

O Curso de Graduação em Medicina terá projeto pedagógico centrado no aluno como sujeito da aprendizagem e apoiado no professor como facilitador e mediador do processo, com vistas à formação integral e adequada do estudante, articulando ensino, pesquisa e extensão, esta última, especialmente por meio da assistência (BRASIL, 2014, p.12).

Portanto, pode-se dizer que a prática andragógica aumenta a autonomia do estudante, podendo escolher como aprender em consonância com seus objetivos; consolidando assim a visão sobre os fatores de sucesso na construção do conhecimento em que o instrutor ou professor atua como mediador e orientador das escolhas dos aprendizes, disponibilizando ambientes e ferramentas adequadas para a eficácia do processo.

\section{A ORGANIZAÇÃO DO CURRÍCULO NA PERSPECTIVA ANDRAGÓGICA}

Na Andragogia, a aprendizagem centra-se na resolução de situações-problema, em contraposição a um ensino centrado em uma disciplina (KNOWLES, 1980). Nesse 
sentido, a organização de um currículo deve ser voltada para a compreensão de problemas cotidianos, levando em conta o contexto socioeconômico em que o aprendiz está inserido, com metodologias adequadas a esse modelo. Segundo Berbel (2011), o conhecimento é produzido por meio da participação ativa dos alunos na resolução de problemas reais.

No curso de medicina, o estudante deverá estar em contato com o serviço, integrando o ensino à sua realidade de saúde, possibilitando aprender com as situações do seu dia-a-dia, como explicita o artigo 23 das DCN's.

Os conteúdos fundamentais para o Curso de Graduação em Medicina devem estar relacionados com todo o processo saúde-doença do cidadão, da família e da comunidade e referenciados na realidade epidemiológica e profissional, proporcionando a integralidade das ações do cuidar em saúde (BRASIL, 2014, p.10).

O trecho evidencia a necessidade de construir um curso pautado em conteúdos que privilegiem uma aprendizagem ampla e baseada no contexto de vida das pessoas. Esse mesmo artigo, na sua íntegra, ressalta os conteúdos imprescindíveis para consolidação da aprendizagem na Medicina, reforçando que este currículo deve ter um caráter transversal e que leva em consideração as dimensões biológicas, psíquicas e sociais.

Para Moreno (2001), a Andragogia objetiva a aquisição de saberes práticos que promovam reflexão e interfiram em todos os âmbitos da vida do aprendiz, desde individuais até os relacionais, mostrando que esse caminho deve ser seguido na formação do sujeito na perspectiva de uma educação para adultos. Ausubel (2003) diz que um material bem selecionado contribui para ampliar o conhecimento do adultoaprendiz.

Além disso, para ser considerada uma prática andragógica, tal currículo precisa ser construído em torno das necessidades dos alunos, envolvendo a participação desses no diagnóstico das necessidades educacionais e na elaboração do plano do seu curso (KNOWLES, HOLTON, SWASON, 2009; NOFFS, RODRIGUES, 2011). Portanto, “o projeto pedagógico do Curso de Graduação em Medicina deverá ser construído coletivamente" e "centrado no aluno como sujeito da aprendizagem", pautando-se em um currículo que respeite "o pluralismo de concepções e a diversidade cultural" (BRASIL, 2014, p. 12). Isso ratifica a importância da responsabilização de todos os sujeitos no processo de ensino-aprendizagem, desde a sua concepção. 
Com efeito, não é possível organizar um currículo, no ponto de vista andragógico, sem a utilização de metodologias de ensino que se enquadrem em seu princípio básico, o de aprender a aprender, ou seja, aprender para se desenvolver. No artigo 29, parágrafo II , podemos perceber a importância disso, quando é dito que um curso de Medicina deve "utilizar metodologias que privilegiem a participação ativa do aluno na construção do conhecimento e na integração entre os conteúdos, assegurando a indissociabilidade do ensino, pesquisa e extensão"(BRASIL, 2014, p. 12).

Sendo assim, compreendemos que o currículo médico se orienta por uma abordagem centrada na Andragogia na perspectiva de proporcionar um aprendizado baseado na interação entre prática e teoria, vivenciando-a e favorecendo a discussão e resolução de problemas reais. Berbel (2011), ao parafrasear John Dewey, diz que a ação promove a aprendizagem e aprendemos fazendo. Nota-se, também, a indicação da participação estudantil, efetiva, na construção do seu projeto pedagógico, respeitando o aprendiz em todas as suas esferas e sua maneira de aprender, inclusive no que tange a flexibilidade individual de seus estudos para garantir uma aprendizagem efetiva.

\section{A AVALIAÇÃo PARA O PROGRESSO}

A avaliação ainda é vista como o último passo do processo ensinoaprendizagem, entretanto, em uma concepção que quebra o paradigma do ensino tradicional, ela se insere como processual e progressiva. Para Knowles (1980), na lógica andragógica, a avaliação da aprendizagem é um momento de buscar evidências do progresso obtido, levando em conta as potencialidades e fraquezas que influenciam no aprender. Cabe ao professor auxiliar os alunos a entender esse processo.

No Ensino Médico, principalmente, após a adoção de metodologias ativas no currículo, conforme preconizam as DCN's, a avaliação se torna algo complexo para o professor, pois esse deve estar atento a diferentes aspectos do estudante.

O Curso de Graduação em Medicina deverá utilizar metodologias ativas e critérios para acompanhamento e avaliação do processo ensino-aprendizagem e do próprio curso, bem como desenvolver instrumentos que verifiquem a estrutura, os processos e os resultados, em consonância com o Sistema Nacional de Avaliação da Educação Superior (SINAES) e com a dinâmica curricular definidos pela IES em que for implantado e desenvolvido (BRASIL, 2014, p.13). 
O Sistema Nacional de Avaliação da Educação Superior (SINAES), criado pela Lei $10.861 / 2004$, foi um marco no processo avaliativo das Instituições de Ensino Superior (IES) no Brasil (BRASIL, 2004). Essa lei tem enfoque na avaliação tanto das instituições quanto dos estudantes pertencentes a elas, por meio de diversos mecanismos, tais como a autoavaliação e o Exame Nacional de Desempenho do Estudante (ENADE), que são realizados por alunos. Tais instrumentos são importantes por servirem como estímulo para as IES, fomentando a cultura de avaliação do ensino. Além disso, esse processo é necessário por constituir uma das condições para funcionamento dessas instituições, sendo regulada pela União (BRASIL, 1996). Desse modo, a avaliação constitui importante etapa no processo de manutenção de uma IES, bem como de mensuração da qualidade do ensino oferecido por ela.

Segundo Sakamoto e Verástegui (2010), o processo de avaliação não é simples e deve procurar o desenvolvimento do indivíduo, sendo realizada a vida toda, confundindo-se, inclusive, com o processo de viver. A avaliação precisa promover o autoconhecimento e, como relata Luckesi (2002), é um ato de amor, sendo acolhedora, integrativa e inclusiva, devendo ser qualitativa e não quantitativa. Nesse contexto, a avaliação formativa se sobressai por ser um importante instrumento para cumprir o propósito da continuidade no processo e, principalmente, levando em conta o desenvolvimento cognitivo do estudante. Assim, o graduando de Medicina deverá

\footnotetext{
[...]comprometer-se com seu processo de formação, envolvendo-se em ensino, pesquisa e extensão e observando o dinamismo das mudanças sociais e científicas que afetam o cuidado e a formação dos profissionais de saúde, a partir dos processos de autoavaliação e de avaliação externa dos agentes e da instituição, promovendo o conhecimento sobre as escolas médicas e sobre seus egressos (BRASIL, 2014, p.3).
}

Essa perspectiva reforça a avaliação qualitativa como ferramenta importante para o processo de desenvolvimento do aluno e o coloca como responsável pela construção do seu saber, compreendendo a realidade que o cerca. Na perspectiva andragógica, essa autoavaliação deve ser mediada por um facilitador que conduz aos objetivos de aprendizagem (NOGUEIRA, 2004). E no curso de Medicina, "as avaliações dos estudantes basear-se-ão em conhecimentos, habilidades, atitudes e conteúdos curriculares desenvolvidos, tendo como referência as DCN's objeto desta Resolução" (BRASIL, 2014, p. 13). 
As DCN's do curso médico garantem uma abordagem avaliativa pautada nos princípios da Andragogia, desde o entendimento da participação e envolvimento do aluno da avaliação e percepção das aprendizagens até a concepção do professor como orientador desse processo. Inclusive, é preconizado, no documento, o envolvimento dos docentes na consolidação de um projeto pedagógico em uma proposta formativa, englobando estratégias de ensino ativas. Cabe à IES efetivar tal abordagem, conduzindo para um modo de avaliar qualitativo e preocupando-se com o progresso da aprendizagem.

\section{CONSIDERAÇÕES FINAIS}

Portanto, pode-se dizer que a mudança de paradigmas no ensino na Medicina tem suas interconexões e, dentre essas, destaca-se a formação dos futuros profissionais da saúde que deverá ser pautada em princípios andragógicos, uma abordagem importante no aprendizado, arrolada no repensar das práticas pedagógicas, bem como na democratização do saber que deverá ser construído coletivamente.

Podemos afirmar que a obrigatoriedade do uso das metodologias ativas no curso médico, regido pelas DCN's, garante os seguintes princípios andragógicos: diagnóstico de necessidades individuais; a formulação de programas objetivos; o envolvimento dos estudantes no processo de planejamento do aprender e professores como guia; a condução da experiência do ensino-aprendizagem como um processo de mútua responsabilidade entre alunos e professores; e a avaliação da aprendizagem. Entretanto, o princípio da construção de um clima da aprendizagem favorável à prática andragógica é abordado de maneira superficial, não sendo abordado em sua completude.

Ainda há o que evoluir na elaboração de DCN's que contemple todos os requisitos do modelo andragógico. À guisa de conclusão, pode-se dizer que os modelos andragógicos estão evoluindo e se tornando importantes no aprendizado nas Ciências Médicas, salutar na condução do adulto-aprendiz.

\section{REFERÊNCIAS}

ARAGÃO, M.N.; SOARES, I.G. (Trans) formando e ousando o método de ensino em enfermagem no cuidado à saúde mental. Revista Portuguesa de Enfermagem de Saúde Mental, n.12, p.59-64. 2014. 
AUSUBEL, L.G.C. Ensinar, aprender, apreender e processos de ensinagem. In: L.G.C. Anastasiou \& L.P. Alves (Eds). Processos de Ensinagem na Universidade: pressupostos para as estratégias de trabalho em aula. Joinville: Univille, 2003.

BARDIN, L. Análise de Conteúdo. São Paulo: Edições 70, 2011.

BELLAN, Z. Andragogia em ação: como ensinar sem se tornar maçante. São Paulo: Z3, 2005.

BERBEL, N.A.N. As metodologias ativas e a promoção da autonomia de estudantes. Semina: Ciências Sociais e Humanas. v. 32, n. 1, p,24-40. 2011.

BRASIL. Lei no 9.394, de 20 de dezembro de 1996. Disponível em: < http://www.planalto.gov.br/ccivil_03/Leis/L9394.htm>. Acessado em: 03 set. 2019.

BRASIL. Lei no 10.861, de 14 de abril de 2004. Brasil, 2004. Disponível em: <http://www.planalto.gov.br/ccivil_03/_ato2004-2006/2004/lei/110.861.htm>. Acesso em: 03 set. 2019.

BRASIL. RESOLUÇÃO CNE/CES Nº 3, de 20 de junho de 2014. Institui as Diretrizes Curriculares Nacionais do Curso de Graduação em Medicina. Diário Oficial da União. Brasília, Seção1, p.8-11, 2014.

BRASIL. Ministério da Ciência e Tecnologia. Conselho Nacional de desenvolvimento Científico e Tecnológico. Áreas do conhecimento: Ciências da Saúde. 2019.

Disponível em: http://www.cnpq.br/areasconhecimento/4.htm. Acesso em 06/09/2019. CEZAR, P.H.N. et al. Transição paradigmática na educação médica: um olhar construtivista dirigido à aprendizagem baseada em problemas. Revista Brasileira de Educação Médica, v. 31, n.3, p.212-22. 2010.

DARBYSHIRE, P. In defence of pedagogy: a critique of the notion of andragogy. Nurse Education Today, v. 13, p. 328-335, 1993.

DRAGANOV, P.B.; FRIEDLANDER, M.R.; SANNA, M.C. Andragogia na saúde: estudo bibliométrico. Esc. Anna Nery [online]. 2011, vol.15, n.1, pp.149-156. ISSN 1414-8145. Disponível em: http://dx.doi.org/10.1590/S141481452011000100021. Acesso em 05/07/2019

FORTE, F.D.S. et al. Portifólio como estratégia de avaliação de estudantes de odontologia. Trabalho, Educação e Saúde, v.13, p.25-38. 2015.

FUJITA, J.A.L. et al. Uso da metodologia da problematização como Arco de Maguerez no ensino sobre brinquedo terapêutico. Revista Portuguesa de Educação, v.29, n. 1, p.229-58. 2016. 
KNOWLES, M.S. The modern practice of adult education: from pedagogy to andragogy. 2 ed. Nova York: Association Press, 1980.

KNOWLES, M. S.; HOLTON, E. F.; ESWANSON, R. A. Andragogía: El aprendizaje de los adultos (M. A. IzquierdoCastañeda, Trans.,3rd ed.). México: Oxford University Press. 2006.

KNOWLES, M.S.; HOLTON III, E.F.; SWASON, R.A. Aprendizagem de resultados: uma abordagem prática para aumentar a efetividade da educação corporativa. Rio de Janeiro: Elsevier, 2009. 388 p.

LUCKESI, C. Avaliação da aprendizagem na escola e a questão das representações sociais. Eccos Revista Científica, Universidade Nove de Julho, São Paulo, v.4, n.2, p.79-88. 2002.

MORENO, L.C. Educação para adultos: uma alternativa para o desenvolvimento profissional. 2001. Disponível em:

<http://www.rh.com.br/Portal/Desenvolvimento/Artigo/3178/educacao-para-adultosuma-alternativa-para-o-desenvolvimento-do-profissional.html>. Acesso em: 03 set. 2019.

NOFFS, N.A.; RODRIGUES, C.M.R. Andragogia na Psicopedagogia: a atuação com adultos. Revista Psicopedagogia. v. 28, n. 87, p.283-92. 2011.

NOGUEIRA, S.M. A andragogia: que contributos para a prática educativa? Revista Linhas, v.5, n. 2, p.1-23. 2004.

OLIVEIRA, A.B. Andragogia, facilitando a aprendizagem. Educação do Trabalhador, v. 3.1999.

OLIVEIRA, A.B. de. A Essência Andragógica para Empresas. MEd Education. University of Minnesota - USA. Instituto Andragógico de Desenvolvimento Humano: Iand, 2011.

SAKAMOTO, B.A.M.; VERÁSTEGUI, R.L.A. Avaliação como ato de amor e não de exclusão. In: II SIMPÓSIO NACIONAL DE EDUCAÇÃO: INFÂNCIA, SOCIEDADE E EDUCAÇÃO. 2010, Cascavel. Anais Cascavel: UNIOESTE, 2010, p. 1-16.

XAVIER, A. S.; KOIFMAN, L. Educação superior no Brasil e a formação dos profissionais de saúde com ênfase no envelhecimento. Interface (Botucatu). v.15, n..39, p.973-984. 2015. ISSN 1414-3283. Disponível em: http://dx.doi.org/10.1590/S1414-32832011005000019. Acesso em 03/09/2019. 